\title{
Gênero, sexo e escuta na voz em performance
}

Gender, sex and listening on the voice in performance

Bárbara Biscaro ${ }^{1}$ 


\section{Resumo}

Neste artigo são tecidas reflexões acerca da relação entre os estudos de gênero e estudos da vocalidade em performance, criando entrelaçamentos entre os campos da música e do teatro. Partindo das noções de feminismo e gênero, o texto traça apontamentos acerca das relações entre as classificações vocais na música erudita ocidental e a sociedade patriarcal na qual esse tipo de música fo criada. O texto aborda também os aspectos tímbricos da voz, a androginia, o conceito de queer listening, criando ainda paralelos com os trabalhos de artistas como Demetrio Stratos e Laurie Anderson.

Palavras-chave: Voz em performance gênero; escuta queer; música

\section{Abstract}

In this article are made reflections bout the relationship between the studies in gender and vocality in performance, tangling the fields of music and theater. Starting from the notions of feminism and gender, the text construct notes about the relationship between the vocal classification in the western music and the patriarcal society where this kind of music was created. The text aproach also the aspects of timbre, androgyny, the queer listening concept, creating also parallels with the work of artists such as Demetrio Stratos and Laurie Anderson.

Keywords: Voice in performance; gender; queer listening; music 
cação biológica como único argumento para a identificação do ser homem e do ser mulher, procurando descolar os aspectos biológicos dos aspectos sociais. Os estudos feministas mostraram que

o conceito de gênero está colado, no Ocidente, ao de sexualidade, o que promove uma imensa dificuldade no senso comum - que se reflete nas preocupações de separar a problemática da ident dade, está marcada pela escolha do objeto de desejo (Grossi, 1998, p. 4).

Ou seja, a explicação biológica (que delimita as características anatômicas sexuais dos corpos) passa a ser tomada como apenas uma das diversas versões do que se pode entender como sexualidade e como gênero, já que aspectos sociais, políticos e culturais passam a ter um peso significativo na ideia de construção de identidade de gênero, operando sempre de forma relacional. A voz em performance, imersa nesse contexto, vai ao longo da história da cultura ocidental não só reforçar os valores de uma cultura patriarcal como indicar quais corpos e quais vozes estavam autorizadas a constituir-se modelos do ser (e soar) homem e o ser (e soar) mulher. As vocalidades masculina e feminina, assim como os corpos que as constituíam, foram forjadas também segundo projetos estéticos fortemente baseados em valores morais construídos socialmente como a religião, a ciência e a cultura predominante. Desconfiar dos padrões vocais impostos culturalmente como "naturais" pela biologia ou pelo sexo, no estudo da voz, seria uma primeira atitude na direção da construção de vocalidades para a cena que privilegiam uma discussão não só estética, mas ética e social.

Um dos exemplos de padrões vocais construídos nessa perspectiva é a classificação das vozes no canto erudito ocidental - soprano, tenor, baixo, contralto, barítono e mezzo soprano. Ampliando a discussão sobre gênero, Grossi explica:

Gênero serve, portanto, para determinar tudo que é social, cultural e historicamente determinado. No entanto, como veremos, nenhum indivíduo existe sem relações sociais, isto desde que se nasce. Portanto, sempre que estamos referindo-nos ao sexo, já estamos agindo de acordo com o gênero associado ao sexo daquele indivíduo com o qual estamos interagindo (Ibidem, p. 5).

Essa reflexão abre precedentes para se pensar a construção de uma vocalidade específica separada em vozes masculinas e femininas como uma construção socia e histórica. Vale lembrar que até meados do século XVIII a música vocal no ocidente tem predominância sobre a música instrumental e o corpo que, nesse contexto, estava inserido dentro dos paradigmas ditados pela religião (a Igreja Católica e a Reforma Luterana, principalmente) e pela sociedade, já que a maioria dos compositores e musicistas eram homens, brancos e imersos em uma sociedade com regras específicas para a manifestação do ser homem e do ser mulher.

O surgimento da ópera como gênero dramático no século XVII inaugura uma produção cênica que sedimenta a classificação vocal, separando primeiro os timbres vocais masculinos e femininos, e depois classificando as vozes de acordo com as tes-

situras graves e agudas dentro de um padrão de canto especifico que se tornou, por fim, um sistema hegemônico ainda presente em nossa cultura musical hoje. Segundo - Dicionário Groove de Música, "a classificação da voz nos registros de cabeça, garganta e de peito já era conhecida no século XIII. A voz de cabeça seria descrita hoje como falsete" (Dicionário Groove, 1994, p. 165). Portanto, o sistema de classificação sofreu alterações e revisões, mas desde o século XVIII nunca dissolveu, por exemplo, a separação entre vozes masculinas e vozes femininas. Mas, isso não quer dizer que não existiram tensões entre essa acepção binária entre voz de homem e voz de mulher: os homens com vozes ditas "femininas" e as mulheres com vozes ditas "masculinas" sempre existiram e a eles foi criado um lugar especial na cadeia classificatória vocal, social e estética da música vocal.

Lendo A carta ${ }^{6}$ do italiano Girolamo Mei, um dos humanistas precursores da criação da Ópera na Itália do século XVI, não existe nenhum discurso fundamentado na ciência ou na biologia (e anatomia) dos corpos masculinos e femininos para tal classificação. Segundo ele:

Visto que a música que concerne ao canto gravita em torno das qualidades da voz, nisto, especialmente, em ser aguda, média ou grave, pareceu-me que deveria ser primordial que a virtude dessa arte repousasse em seu principal fundamento necessariamente nestas disposições [tímbricas]. E, ademais, não havendo semelhança entre cada uma dessas paixões [grave, média, aguda], seria irrazoável que tivessem as mesmas faculdades (Mei apud Chasin, 2004, p. 44).

Mei, imerso em um contexto no qual as paixões são a forma de dissecar o corpo e suas manifestações, atribui às qualidades vocais uma classificação na qual as vozes agudas poderiam expressar uma gama específica de paixões, enquanto as graves, outras, criando uma lógica dramatúrgica-musical baseada nos aspectos tímbricos da voz cantada. Ibaney Chasin, tradutor e comentador do tratado de Mei, explica:

Então, como é pelo agudo, médio e grave, prossegue Mei, que o dizer engendra e distingue paixões - diversas, contraditórias, portanto não cambiáveis entre si tais disposições sonoras tornam o canto, antes e acima de tudo, portador singular dos afetos, da esfera da sensibilidade (Chasin, 2004, p. 45).

Ou seja, até esse momento, o timbre e a tessitura da voz estavam ainda descolados das imagens dos corpos que produziriam essas paixões: a normatização entre voz feminina em corpo de mulher e voz masculina em corpo de homem iria se consolidar aos poucos não somente se referindo aos sons das vozes, mas aos papéis da mulher e do homem nas construções dramatúrgicas das óperas - pois, posteriormente à composição musical, o espectador veria esses homens e mulheres na cena, colando os corpos e suas normas sociais ao som das vozes.

As explicações anatômicas e biológicas viriam muitos anos depois: é evidente que as diferenças anatômicas entre corpos de homens e mulheres produziriam diferentes particularidades sobre a voz da mulher ou do homem. Hormônios, caracte- 
rísticas musculares, capacidade pulmonar e outras diferenciações seriam apontados como uma explicação tardia a essa divisão. Mas partindo do princípio que existiriam particularidades anatômicas e biológicas referentes não só à diferenciação homem e mulher, mas entre mulheres e mulheres ou homens e homens, como criar um sistema que abarcasse a diversidade dos corpos e suas configurações únicas? Janete E Haouli, musicóloga, explica:

\section{[...] a simbologia aplicada aos tenores, sopranos e baixos no século XIX já pre- figura uma certa sistematização bem-acabada dos atributos vocais. Os timbres eram escalonados segundo uma identidade, um traço comum a todos que se en- caixassem em determinada extensão. Havia, portanto, um conceito a ser obedeci- do para a melhor adequação das vozes humanas à produção musical da época (E Haoulli, 2002, p. 75)}

Outra explicação para a manutenção desse sistema é o caráter moralizante impresso nessa manifestação da voz em cena. El Haouli demonstra que, nesse contexto, a realidade puramente física, corporal, vai atender aos imperativos da "boa" téc-
nica. A voz é considerada como um instrumento, uma máquina perfeitamente do-
mesticável a serviço de uma estética harmoniosa e em nenhum momento anárqui-
ca. O rúdo, o "desafinar" devem ser exorcizados daquele mundo que determinou
uma certa "moral" da voz (Ibidem).

Na busca pelas vozes perfeitas, o século XVII criou suas contradições: viu a ascensão e prestígio da figura dos castrati ou cantanti evirati - homens castrados na infância que aliariam o timbre agudo (apreciado quase como um fetiche na forma musical operística) com a potência muscular do homem para atingir uma vocalidade considerada única. Os homens castrados na música ocidental remontam o século XV (apesar de haverem indícios que existiriam homens castrados cantores desde as civilizações antigas). Segundo o Dicionário Groove de Música, "os castrati foram usados pela Igreja Católica Romana por mais de 300 anos e ocuparam uma posição dominante na ópera dos séculos XVII e XVIII" (Dicionário Groove, 1994, p. 177). As mulheres, proibidas de cantarem na Igreja não poderiam integrar os coros, formados apenas por homens:

Embora a arte do canto seja uma das formas mais antigas de se fazer música, acredita-se, em geral, que os estilos do canto ocidental moderno remontam apenas ao final do século XVI. Os relatos sobre a arte do canto anteriores são em pequeno número de difícil interpretação. É provável que a voz masculina aguda fosse preferida (em muitos contextos eclesiásticos, o canto de mulheres era proibido), e na Idade Média o cantor virtuose, capaz de uma interpretação brilhante, desempenhava um papel importante na elaboração de certos tipos de canto (Ibidem, p. 165).

As linhas mais agudas dos cantos litúrgicos poderiam ser cantadas por meninos (até a idade da mudança vocal, na pré-adolescência) e pelos falsetistas, homens que conseguiam alcançar os tons mais agudos, mesmo que com pouca potência ou briIho vocal. A ascensão dos castrati, portanto, também remonta uma necessidade de substituir o timbre e a voz feminina com o único corpo permitido a ter voz no recinto das Igrejas: O corpo do homem. Ate meados do seculo XVI "a maior parte da música

secular destinava-se apenas a vozes masculinas (incluindo o falsete), mas a partir do final do século XVI as vozes femininas entraram cada vez mais em uso [...]" (Ibidem p. 165). É interessante traçar um paralelo com o Teatro Elisabetano, que começa a aceitar mulheres na cena somente a partir do século XVI. Até então era corrente o uso de meninos e jovens para dar verossimilhança aos papéis femininos do teatro elisabetano - na impossibilidade da mulher se fazer presente, procuram-se meninos ou homens com vocalidades que se aproximavam das qualidades dos falsetistas (e no teatro, também com um aspecto físico verossimilhante) que se aproximam sonoramente ao timbre atribuído ao feminino (no caso, o agudo), ocupando a lacuna deixada pela proibição da mulher no recinto do teatro.

A presença ambígua e andrógina na cena seria objeto de culto na cultura musical da Ópera dos séculos XVII e XVIII. O poder associado à figura dos castrati exerceu um verdadeiro fascínio entre compositores e espectadores, sendo que diversos papéis das Óperas Barrocas foram escritos para essa figura que associaria uma corporalidade masculina a um timbre vocal feminino - criando nessa discrepância a sua particularidade andrógina. Assim como existiram também as mulheres que cantavam papéis masculinos, as chamadas Ermafrodite Armoniche, pesquisadas atualmente pelo musicólogo italiano Marco Beghelli ${ }^{-}$- mulheres cantoras com timbres graves que se aproximavam da vocalidade instituída como masculina e, do mesmo modo que os castrati, operavam esse descolamento entre sexo, gênero e vocalidade na cena operística, explorando a androginia vocal e um estilo de execução vocal chamado também de voce doppia (voz dupla). Mas a existência dessas figuras ambíguas na cena se deu no auge do desenvolvimento do estilo vocal chamada bel canto, que seria caracterizado por "estilo de canto desvinculado de toda preocupação do realismo dramático e de verossimilhança em relação à situação, ao caráter e ao sexo do personagem e tendente a uma abstração puramente musical" (Enciclopédia Garzanti apud El Haoulli, 2002, p. 76). A duplicidade dessas vozes e a androginia eram exploradas como recursos estéticos do canto, sendo reforçada por cantores/as, compositores e público de acordo com as convenções e o gosto de sua época.

Essa predominância do som e do timbre da voz sobre a verossimilhança da cena reinaria até o século XIX, momento em que a ordem social, moral e cultural burguesa vai engessar definitivamente as vozes nos corpos classificados no binômio homem/ mulher e começar a cobrar um comportamento cênico-vocal espelhado nas relações sociais e de gênero de seu tempo. Quando a produção operística passa a ser sustentada pela compra de ingressos de uma burguesia emergente que quer ocupar os espaços da dita "alta cultura" - antes reservados para a nobreza -, as produções sofrem as transformações necessárias para se adequarem ao gosto e aos valores de seus "fregueses". El Haouli explica que

as personagens de operas passaram a representar as paixões e os conflitos amorosos, não raro sociais. Há o aparecimento de um drama mais elaborado e veross mil. Para isso, tornam-se necessárias idealizações correlatas. Homens represenA obra de Beghelli, escrita com Raffaele Talmelli que trata dessa
emática é Ermafrodite Armoniche - II contralto nell' OOttocento. Itália: Zecchini Edittore, 2011 
tam homens e mulheres representam mulheres. É o sujeito dono de seu destino (El Haoulli, 2002, p. 77)

O que é interessante notar é como essa classificação persiste ainda hoje como padronização das vozes no canto. Mesmo que a música contemporânea, a partir da década de 1950, passe a contestar a necessidade da classificação vocal e trabalhar com outras formas de concretizar a vocalidade musical (quebrando muitas vezes o binômio voz masculina e voz feminina), as práticas pedagógicas pouco fizeram para destituir esse modo de classificação. Homens cantam como homens, mulheres cantam como mulheres - segundo uma vocalidade construída ao longo de quatro séculos, em um contexto específico, com uma moral específica e com fins musicais e sonoros específicos. É interessante notar também como a ligação entre sonoridade vocal e gênero (permitindo associações como, por exemplo, vozes agudas com mulheres e vozes graves com homens) para a vocalidade específica da cena é um fator construído social e culturalmente; o fato das vozes masculinas na música litúrgica terem construído uma noção particular de sonoridade vocal do homem ao longo de séculos abre precedentes para pensar que não existiriam naqueles contextos homens que cantavam como mulheres (como nossos ouvidos hoje poderiam explicar) -, mas homens que desenvolveram vocalidades específicas para as formas musicais exigidas em seu contexto - marcado obviamente pela exclusão das mulheres do recinto da Igreja.

A herança dessa cultura e a sua manutenção no contexto atual só reforça o quanto ainda é possível avançar nos estudos musicológicos, por exemplo, no esforço de diversificar as noções de corpo musical através do estudo de diferentes tradições e práticas musicais em outras culturas, a fim de relativizar essa forma de escutar as vozes separando-as em timbres masculinos e femininos, como se essa fosse uma classificação estável e aplicável a todos os corpos indistintamente.

Quando a subjetividade do cantor ou do performer na cena não se curva a essa convenção, é possível ver surgir trabalhos que aliam a voz em performance a uma pesquisa estética que evidencia um questionamento acerca das noções de gênero e sexo estabelecidas. Vale à pena frisar que questionar essas noções não significa apenas aprender cantos de outras culturas ou simplesmente colocar mulheres em busca de sonoridade graves e homens em busca de sonoridades agudas. Artistas forjados no seio de uma cultura musical instituída podem buscar o questionamento das noções de gênero na vocalidade de seus trabalhos através de muitos caminhos, sempre particulares e quase sempre intransferiveis - pois tratam de corpos específicos buscando estéticas específicas. Não há respostas simples nos caminhos propostos a partir dessas reflexões

Existem trabalhos/contextos artísticos nos quais essas tensões estão mais evi dentes, e a consciência das questões de gênero se tornam uma importante fonte de material para vivenciar/refletir sobre a presença da voz em cena. O gênero então se torna um recurso estético amplificado por questões singulares, e as vozes que emergem desses contextos (e seus textos, suas sonoridades, sua musicalidade, seus artifícios cênicos) são vozes específicas.

O cantor e compositor grego Demetrio Stratos ${ }^{8}$ (1945-1979) foi um dos mais interessantes pesquisadores vocais do século XX. Sua obra é fruto de seus experimentos acerca da sua própria vocalidade e continua sendo referência para diversas gerações de pesquisadores vocais voltados para as artes cênicas, música e performance art. Transcrevo aqui um trecho de entrevista com ele que consta no livro de Janete El Haouli:

Pergunta: Demetrio, você se reconhece andrógino? Resposta: Em meu trabalho musical aparece claramente a minha natureza andrógina. Tenho duas vozes: uma masculina, uma feminina, e adoto ambas, separadamente e simultaneamente (Stratos apud El Haoulli, 2002, p. 73).

Vale frisar que a vocalidade feminina a que se refere Stratos se constitui na sua capacidade de emitir sons e cantar em registros agudos que tradicionalmente são associados à voz feminina e suprimidos da construção vocal masculina (o mal compreendido falsete, excluído da vocalidade masculina em diversas pedagogias vocais do canto ocidental a partir do século XIX). Stratos desenvolveu a extensão de sua voz sem as amarras das convenções do canto erudito ocidental - buscou referências nas formas de canto de outras culturas, como o yodel e o canto harmônico, para construir uma vocalidade única, forjada a partir de seu corpo, sua subjetividade e suas questões pessoais como artista.

A questão do timbre masculino e feminino, abordada até aqui, se amplia atualmente nas discussões sobre queer music e queer listening. Segundo a pesquisadora Guacira Lopes Louro, "efetivamente a teoria queer pode ser vinculada às vertentes do pensamento ocidental contemporâneo que, ao longo do século XX, problematizaram noções clássicas de sujeito, de identidade, de gênero, de identificação" (Louro, 2008, p. 40). Ainda explicando as particularidades da teoria queer, Louro afirma que para os teóricos/as queer, a oposição heterossexualidade/homossexualidade - onipresente na cultura ocidental moderna - poderia ser efetivamente criticada e abalada por meio de procedimentos desconstrutivos" (Ibidem, p. 43). A autora ainda reforça o interesse em romper com estruturas de pensamento binárias como homem/mulher feminino/masculino, buscando noções mais complexas para pensar sexo, sexualidade, gênero e identidade.

O pesquisador britânico Yvon Bonenfant escreve sobre uma possibilidade do desenvolvimento de uma escuta queer baseada fundamentalmente nas características do timbre vocal e na capacidade de uma escuta afetiva e corporal, a partir do conceito de vocalic body. Para o autor a escuta é uma experiência acima de tudo corporal na qual as vozes tocam os corpos - aproximando a noção de audição noção de tato: "a escuta se torna o ato de prestar uma intensa atenção somática aos caminhos que nossos corpos empreendem com os estímulos sônicos ao redor deles. [...] Estes estímulos não são apenas som. Eles são táteis" (Bonenfant, 2010, p. 78, tradução nossa). O ponto sustentado por Bonenfant é que o caminho para pensar uma escuta queer passaria por uma ampliação física da capacidade de escuta dos timbres marcados pela cultura, pelos valores sociais instituídos e pelos modelos construídos por cada um de nós como voz masculina ou feminina - ampliando a noção de escuta e de identidade vocal na direção de tocar ao outro e ser tocado pelas vozes. Dessa

8 Para conhecer mais acerca de Demetrio Stratos, consultar o livro
de Janete El Haouli (2002), que consta na bibliografia deste artigo. 
forma "já que os corpos estão localizados dentro do fazer das vozes queer, ouvintes queer podem talvez captar algumas das variações sutis no timbre que indicam uma 'identidade' ressonante que quer tocar alguém como nós" (Ibidem).

Bonenfant levanta questões importantes para a discussão sobre timbre vocal, escuta e gênero:

A quem é permitido soar e sob quais circunstâncias? A quem é permitido tocar com o timbre de modos a acariciar queerly de outra maneira? Talvez existan qualidades de toque que são sentidos conto aneaças à hegennonia? Certamente e quanto ao timbre em si mesmo? (Ibidem, p. 79).

Para Bonenfant seria uma tarefa para os ouvidos (e para todo o corpo que sente as vibrações sonoras) a dissolução das sonoridades vocais pré-concebidas acerca do feminino e do masculino - compartilhando a responsabilidade entre artistas e espectadores na reconstrução (ou ao menos na relativização) das noções de gênero impressas na vocalidade humana.

Laurie Anderson (1947-), compositora e performer norte-americana, explora em seu trabalho autoral diversas questões ligadas ao gênero aliadas ao contexto sonoro e performático que criou ao longo de mais de quarenta anos de carreira. A pesquisadora norte-americana Susan McClary explica que o uso da tecnologia no trabalho de Anderson é uma escolha estética que continuamente media sonoridade, voz e presença. Mas McClary pontua:

Se o seu trabalho recusa as opções oferecidas pela tradicional dicotomia Homem um corpo feminino muda as dinâmicas de diversas oposições que ela evoca em performance (McClary, 1991, p. 138, trad. nossa)

Ou seja, o corpo feminino é um fator dado que em si expressa ideais políticos, sociais e éticos na cena. McClary complementa:

Os corpos das mulheres na cultura Ocidental foram quase sempre vistos como objetos de exibição. Às mulheres raramente foi permitida a ação em arte, mas ao invés disso, elas foram restritas ao decreto - sobre e através de seus corpos - dos homens. Séculos dessa tradicional divisão do trabalho cultural recaem em Anderson (ou qualquer performer mulher) quando ela atua, sempre ameaçando a derson (ou qualu per

o prazer da contemplação masculina (Ibidem).

Laurie Anderson assume outras provocações relacionadas ao gênero em seus trabalhos: o constante trabalho com aparatos tecnológicos para a proliferação e subversão da sua própria sonoridade vocal - isso desde meados da década de 1970 - transcendem a visão da inacessibilidade da mulher ao manuseio e domínio das máquinas, como aponta McClary: "mulheres nessa cultura são desencorajadas de até mesmo aprender sobre tecnologia, em parte para que elas possam continuar a representar a Natureza autêntica e não-mediada" (Ibidem). Pode parecer banal o domínio da tecnologia em performance para as jovens artistas de hoje, mas imagine o que re- presentou isso na década de 1970. Outra provocação é o uso da androginia como um recurso estético. A adoção de uma figura andrógina enquanto trabalhava no álbum United States (1981) marca uma escolha: "sua androginia minimiza sua sexualidade, a qual, dados os termos da tradição, sempre ameaça se tornar todo o show" (Ibidem) Ou seja, a figura de uma mulher que compõe, toca, canta e conta histórias em cena carrega em si informações capazes de suplantar, ameaçar um projeto estético, perdendo um importante espaço de ação poética para diversas convenções já consolidadas da presença da voz feminina em performance.

É interessante notar como a androginia no trabalho de Anderson opera de forma diferente do caso de Demetrio Stratos: se em Stratos androginia residia no timbre vocal, para Anderson a androginia passa pela construção da visualidade do corpo e o modo como seu corpo-voz é colocado em performance, a serviço de uma construção estética particular que alia aspectos visuais, auditivos e de linguagem.

A proliferação da figura da intérprete-criadora nas últimas décadas, principalmente em campos híbridos de criação (nos quais as fronteiras entre dança, teatro música não aparecem claras) se deve também a um desejo de evidenciar uma subjetividade implícita do corpo em performance: sem mais mediações dos olhares masculinos (ou mesmo de outrem), aspectos como inovação estética, composição sonora ou dramaturgia passaram a se referir a corpos, gêneros, vivências e subjetividades específicas. Passaram a evidenciar a subjetividade da artista que não aceita mais mediações de seus procedimentos estéticos e poéticos, fazendo do próprio corpo presença, discurso, procedimento, subjetividade e materialidade da cena. McClary fala sobre Laurie Anderson:

Entretanto, Laurie Anderson é uma performance artist de quem as prioridades levam ela não somente a reconhecer mas a insistir sobre sua identidade de gêner em seu trabalho, e na música como um dos componentes mais teatrais. Mas não e nem um pouco óbvio como fazer diferenças de gênero audíveis em música, nem existe uma única posição teórica sobre esse assunto (Ibidem, p. 140).

Como fazer o gênero audível na música realmente não é uma resposta simples, e talvez o modo de respondê-la seja muito variado, como evidencia McClary. O fato de Anderson ser compositora e performer de suas próprias criações pode ser em si um modo de tornar audíveis questões de gênero na arte? Como as questões de gênero são audiveis nas vozes em cena?

O foco nos aspectos tímbricos da voz, passando pelas reflexões de Girolamo Mei no século XVI até as noções de queer listening no século XXI pode ser uma pista sobre como estimular uma escuta (e conseqüente prática) vocal crítica - conhecer e ultrapassar as categorizações já existentes (e marcadas por territórios de poder já instituídos) em direção a novas formas de diferenciar ou aproximar as vozes, suas cores e seus propósitos em performance. Ações com foco nos aspectos tímbricos podem transportar as pesquisas vocais para territórios um pouco mais complexos do que os binarismos já discutidos durante este texto, provocando deslocamentos importantes da forma como se vive a vocalidade voltada para a cena.

Questionar a forma como as vozes são vivenciadas e ouvidas na cena - seja partindo de culturas hegemônicas com territórios bem estabelecidos como a música 
erudita no Ocidente, seja partindo de pesquisadores e performers vocais específicos como Demetrio Stratos e Laurie Anderson que forjaram na particularidade suas próprias versões de vocalidade, estética e identidade - é um importante passo para pensar os entrelaçamentos éticos, sociais e políticos que a pesquisa acerca da vocalidade na cena pode propor. Perceber como essas questões estão subjacentes às escolhas estéticas, dramatúrgicas e pedagógicas no campo da pesquisa vocal para a cena pode impulsionar abordagens artísticas e metodológicas interessantes, capazes de propor percepções e subversões que emergem em contextos específicos, em corpos-vozes particulares - ampliando os clichês acerca do sexo, identidade ou gênero na expressão da vocalidade humana.

\section{Referências}

BONENFANT, Yvon. Queer listening to queer vocal timbres. In: Performance Research - On listening. Volume 15 / n. 3. United Kingdom: Routledge, 2010.

CHASIN, Ibaney. O Canto dos Afetos - um dizer humanista. São Paulo: Perspectiva, 2004.

CANTO, TIPOS DE. In: Dicionário Groove de Música: edição concisa. Editado por Stanley Sadie, Editora Assistente Alison Latham. Tradução: Eduardo Francisco Alves. Rio de Janeiro: Zahar, 1994.

CASTRATO. In: Dicionário Groove de Música: edição concisa. Editado por Stanley Sadie, Editora Assistente Alison Latham. Tradução: Eduardo Francisco Alves. Rio de Janeiro: Zahar, 1994.

EL HAOULI, Janete. Demetrio Stratos: em Busca da Voz-Música. Londrina: Gráfica e Editora Midiograf, 2002.

GROSSI, M. P. Identidade de Gênero e Sexualidade. Antropologia em Primeira Mão. Florianópolis, p. 1-18, 1998. (versão revisada - 2010) - consultado em http://www. miriamgrossi.cfh.prof.ufsc.br/publicacoes.html . Acesso em: 07 mar. 2013.

LOURO, Guacira Lopes. Um Corpo Estranho - ensaios sobre sexualidade e teoria queer. Belo Horizonte: Autêntica, 2008.

MCCLARY, Susan. Feminine Endings - music, gender and sexuatlity. Minnesota: University of Minnesota Press, 1991.

Recebido em 01/04/2014

Aprovado em 30/06/2014 